\section{Bad experiences in the hospital: the stories keep coming}

\section{Wendy Levinson, ${ }^{1}$ Kaveh G Shojania ${ }^{1,2}$}

In this issue of the journal, two patients narrate stories about their disappointments with a healthcare system that did not seem to care about them as people. Michel Villette, a sociologist in France, tells the story of his hip surgery in an 'elite' French orthopaedic hospital. ${ }^{1}$ Melissa McCullough, a bioethicist and attorney, relates the story of her more prolonged ordeal with an uncommon neurological diagnosis in the National Health System in the UK. $^{2}$ Despite these differencesundergoing a routine orthopaedic procedure in an exclusive private care setting versus diagnosing and managing a far from routine neurological problem in a public health system-these two stories share fundamental features. Both recount numerous failures of the system to deliver patient-centred care. Similar stories could be told about both the private and public healthcare systems in North America. And these stories are consistent with those of many other patients, including ones written by physicians when they (or their family members) have been patients, ${ }^{3-5}$ as well as accounts from patients, like the current authors, who, though not clinicians, have professional backgrounds that particularly equip them to identify and articulate deficiencies in healthcare

\footnotetext{
${ }^{1}$ Department of Medicine, University of Toronto, Toronto, Canada; ${ }^{2}$ Sunnybrook Health Sciences Centre and University of Toronto Centre for Patient Safety, Toronto, Canada

Correspondence to Dr Wendy Levinson, Sir John and Lady Eaton Professor and Chair, Department of Medicine, University of Toronto, Suite 3-805,

R. Fraser Elliott Building, 190 Elizabeth Street, Toronto, ON M5G 2C4, Canada;

wendy.levinson@utoronto.ca
}

delivery. ${ }^{6}{ }^{7}$ Why do these stories of bad patient experiences continue to appear from every health care system?

Broadly, these stories illustrate gaps in quality in the dimension of 'patient-centred care', one of the six dimensions of quality in the Institute of Medicine definition. ${ }^{8}$ Metrics of patient-centred care in the hospital setting, like the commonly used Consumer Assessment of Healthcare Providers and Systems (CAHPS) survey, ${ }^{9} 10$ include several dimensions: communication with the nurses and physicians, the environment of the hospital (how clean is the hospital and how quiet is it at night), the experience of care (getting help when you need it; pain control) and planning for discharge. CAHPS surveys also assess the patient perspective on a variety of aspects of care in the outpatient setting. These widely used and well-validated CAHPS surveys perfectly capture the issues and gaps in quality of care raised by Villette and McCullough. One CAHPS item, 'During this hospital stay, after you pressed the call button, how often did you get help as soon as you wanted it?', would generate a very low score from both authors/patients, but certainly from McCullough who rang the call bell incessantly for $20 \mathrm{~min}$ without response. For another survey item, 'During this hospital stay, how often was your pain well controlled', both patients would give their respective hospitals failing grades.

That care often falls far short of what patients want and expect will come as no surprise to many who work in healthcare, certainty not to those with a focus on quality improvement, as with the readership of this journal.
But, the authors also point out that the overworked and stressed staff members are also unhappy with their inability to provide the kind of care they know is best for patients. The broken 'four cent pull chain' frustrates the nurse who has to fix it, not just the patient. The routinely malfunctioning hospital bed likewise bothered both the nurse and the doctor to whom Villette mentioned it. If these gaps in quality are frustrating to both healthcare providers and to patients, wouldn't fixing them offer benefits to both groups?

We believe that efforts to improve patients' experiences often offer a win-win opportunity to improve the experiences of healthcare workers as well. For example, executive walk rounds ${ }^{11}$ in hospitals often uncover infrastructure problems that frustrate members of the healthcare team because they hinder the ability to provide high quality care. These problems range from usability issues with medical information systems to more mundane, but frustrating, problems with routine equipment, such as beds, storage space, inpatient care areas, and processes for repairing or replacing defective equipment. ${ }^{12} 13$ Our experiences, both of us having worked in a number of major hospitals in the USA and Canada, confirm these findings in the literature. Frontline staff frequently struggle with infrastructure issues that inhibit their ability to deliver high quality care, undermine their work flow and also affect their morale. Many of these same infrastructure problems frustrate patients as much as they do staff. Some patient safety problems thus represent a win-win situation from an organisation's point of view: addressing them improves patient safety and increases the efficiency of frontline staff, as well as the quality of their work life.

An overflowing waiting room, including not just a tearful McCullough $^{2}$ but probably numerous other distressed and frustrated patients and 
their families, generates numerous interruptions for staff, as understandably annoyed and frustrated patients interrupt them to ask when their turn will come. Physicians who have ever worked in a clinic that chronically runs behind schedule, has excessive wait times to make appointments or other basic problems with service quality know that, in such settings, the first 5-10 $\mathrm{min}$ of each patient visit can be consumed by patients recounting their frustrations for how long they have waited, the unhelpful manner of receptionists (as Villette encountered in the admissions department $^{1}$ ) and numerous other problems, from excessive delays in obtaining important investigations (such as McCullough's $\mathrm{MRI}^{2}$ ) to the inconvenience and expense of hospital parking.

Addressing such problems at the system level presents the opportunity to improve patients' experiences as well as the quality of work life for clinicians. Nurses do not enjoy telling patients they will have to wait longer to see a physician. And, physicians would prefer to see patients in a timely manner, not have to tell patients they have to wait weeks to months for important investigations, or explain that the hospital does not have funds to maintain beds in working order (as with one of Villette's physicians ${ }^{1}$ ), among other examples, from unexpected cancellations of operating room times to the cleanliness of hospital wards. For some staff, dealing with these daily frustrations contributes to burnout and even to discourteous or frankly unprofessional behaviour towards patients, as McCullough and Villette experienced in varying degrees.

Unkind or unprofessional behaviour must be addressed in itself when it occurs. But, preventing recurring problems with such behaviours requires addressing the factors that give rise to them, and often this may involve resolving demoralising infrastructure problems and inefficiencies in daily practice that are beyond the capabilities of frontline staff to address without support from senior management. Not all patient safety problems present such win-win opportunities to improve the patient experience while also making work easier for staff. But, the incentive to implement improvements that address such problems is analogous to that for the minority of clinical therapies that improve outcomes and decrease costs. In the language of cost-effectiveness analysis, such therapies (like many vaccines) are 'dominant'. Improvements that appeal to both patients and frontline staff represent similarly 'dominant strategies' for organisations to pursue.

It is perhaps surprising that, despite all the efforts to improve quality of care over the last decade, these deficiencies in patient-centred care remain so common. These persistent failures of patient-centred care reflect the focus on improving other dimensions of quality, such as effectiveness, efficiency and patient safety. Healthcare organisations and their staff tend to concentrate on improving technical aspects of care; patient-centredness can come later if there is time and energy left over (which there rarely is). Yet, studies demonstrate that patients' perceptions of their care are closely linked to the quality of technical care. For example, in a recent study of quality and safety in over 900 hospitals in the USA, patient ratings of overall hospital satisfaction were strongly related to technical performance in all medical and surgical care. ${ }^{14}$ Furthermore, interviewing hospitalised patients can be an excellent source of information about potentially serious and preventable problems in patient safety. ${ }^{15-17}$ Attention to the aspects of care valued and noticed by patients can thus provide an effective method to improve both the technical aspects of care and the patient experience.

The persistent inattention to patients' perspectives and patient- centred care suggests that we need to change our mental model. Often, physicians say things like 'I am referring you to this surgeon. Ignore his bedside manner. He is a good surgeon'. With such statements, we imply that a 'good physician or surgeon' is one who is technically proficient even if he/she is not effective in communicating with patients. Both Villette and McCullough note this focus by their healthcare providers on the technical tasks of care rather than the patient. Medical education has reinforced this problematic compartmentalisation for many years by emphasising the teaching and evaluation of technical competency during medical school and residency, and conversely spending little curricular time and evaluation effort on communication competencies. $^{18} \quad 19$ Furthermore, continuing medical education very rarely addresses knowledge or skills needed to deliver high quality patient-centred care-like teaching skills of informed decision making or disclosing medical errors. ${ }^{10}$ Hence, physicians in practice may lack fundamental and essential skills and yet be considered by peers as a 'good physician'. We must change our model to one that holds that excellence is only possible when a physician has both excellent technical and communication skills.

In addition to health professionals honing their skills, the healthcare setting needs to pursue quality improvement focused on building patient-centred care systems. Root cause analyses can be applied to studying what went wrong in the system for Villette and McCullough. Such investigations would undoubtedly reveal many systems problemsthe lack of communication between hospital units, the response to calls for help and of course fixing the 'four cent pull chain' once instead of on each shift (a remarkably inefficient and time-consuming strategy for all concerned). 
Villette and McCullough tell us stories about their experiencesdisappointingly bad stories. Healthcare professionals cringe to read these stories, as they pride themselves on providing high quality, compassionate care. Yet, the professionals and the system in which they work fall far short. If the approaches presently advocated for analysing and preventing serious medical errors were applied to breakdowns in patientcentred care, we could take a big leap forward-for the quality of patient care and, in many cases, for the work experience and morale of providers.

Competing interests None.

Provenance and peer review Commissioned; internally peer reviewed.

Published Online First 28 September 2011

BMJ Qual Saf 2011;20:911-913.

doi:10.1136/bmjqs-2011-000474

\section{REFERENCES}

1. Villette M. For want of a four-cent pull chain. BMJ Qual Saf 2011;20:986-90.
2. McCullough M. An ethicist's journey as a patient: are we sliding down the slippery slope to sloppy healthcare? BMJ Qual Saf 2011;20:983-5.

3. Berwick DM. Escape Fire: Lessons for the Future of Health Care. New York, NY: The Commonwealth Fund, 2002.

4. Rosenbaum EE. A Taste of My Own Medicine: When the Doctor Is the Patient. New York, NY: Random House, 1988.

5. Southwick F. Who was caring for Mary? Ann Intern Med 1993;118:146-8.

6. Cleary PD. A hospitalization from hell: a patient's perspective on quality. Ann Intern Med 2003;138:33-9.

7. Paget MA. A Complex Sorrow: Reflections on Cancer and an Abbreviated Life. Ed. Marjorie L DeVault. Philadelphia: Temple University Press, 1993.

ISBN:1-56639-041-9.

8. Institute of Medicine. Committee on Quality of Health Care in America. Crossing the Quality Chasm: A New Health System for the 21st Century. Washington, DC: National Academy Press, 2001.

9. Agency for Healthcare Research and Quality. CAHPS ${ }^{\circledR}$ Clinician \& Group Survey and Reporting Kit 2008. http://www.cahps. ahrq.gov/cahpskit/CG/CGChooseQX.asp (accessed 11 Aug 2011).

10. Levinson W. Patient-centred communication: a sophisticated procedure. BMJ Qual Saf 2011;20:823-5.

11. Frankel A, Grillo SP, Baker EG, et al. Patient Safety Leadership WalkRounds at Partners Healthcare: learning from implementation. Jt Comm J Qual Patient Saf 2005;31:423-37.
12. Levtzion-Korach O, Frankel A, Alcalai H, et al. Integrating incident data from five reporting systems to assess patient safety: making sense of the elephant. Jt Comm J Qual Patient Saf 2010;36: 402-10.

13. Shojania KG. The elephant of patient safety: what you see depends on how you look. Jt Comm J Qual Patient Saf 2010;36:399-401.

14. Isaac T, Zaslavsky AM, Cleary PD, et al The relationship between patients' perception of care and measures of hospital quality and safety. Health Serv Res 2010;45:1024-40.

15. Weissman JS, Schneider EC, Weingart SN, et al. Comparing patient-reported hospital adverse events with medical record review: do patients know something that hospitals do not? Ann Intern Med 2008;149:100-8.

16. Weingart SN, Pagovich O, Sands DZ, et al. What can hospitalized patients tell us about adverse events? Learning from patientreported incidents. J Gen Intern Med 2005:20:830-6.

17. Taylor BB, Marcantonio ER, Pagovich O, et al. Do medical inpatients who report poor service quality experience more adverse events and medical errors? Med Care 2008;46:224-8.

18. Levinson W, Pizzo PA. Patient-physician communication: it's about time. JAMA 2011;305:1802-3.

19. Levinson W, Lesser CS, Epstein RM. Developing physician communication skills for patient-centered care. Health Aff (Millwood) 2010;29: 1310-18. 